\title{
An improved, non-isotopic method of screening cells from patients with abnormalities of sexual differentiation for $\mathrm{Y}$ chromosomal DNA content
}

Michal Witt, Karolina Michalczak, Anna Latos-Bielenska, Jadwiga Jaruzelska, Izabela Kuczora, Marisol Lopez

\begin{abstract}
The detection of $45, X / 46, X Y$ mosaicism in patients with abnormalities of sexual differentiation is of crucial diagnostic importance. Here we present application of a PCR based method of detection of alphoid repeats of $Y$ chromosomal origin. The method detects $0.01 \%$ of male DNA on a female DNA background. Out of 28 patients studied, in all cases where the $Y$ chromosome or a part of it containing centromeric sequences was present, a positive amplification signal of $Y$ chromosomal alphoid repeats was detected. In five cases the $Y$ origin of marker chromosomes was diagnosed. The pattern of amplification signal distribution of the SRY gene was identical to that of $Y$ specific alphoid primers, which confirms applicability of this method in the molecular diagnostic laboratory. The other diagnostic advantage is the ability to use dried blood specimens as an easy to handle and efficient source of DNA.

( $(\mathcal{M}$ Med Genet 1993;30:304-7)
\end{abstract}

Several laboratory methods of 'sexing' human DNA have been developed. The focus is generally on the detection of $\mathrm{Y}$ specific chromosomal sequences. ${ }^{1-9}$ These methods are useful not only for prenatal or postnatal diagnosis of sex linked disorders but also for detection of residual host cells in patients with an opposite sex bone marrow transplant (BMT), ${ }^{10}$ for detecting $45, \mathrm{X} / 46, \mathrm{XY}$ mosaicism in patients with Turner's syndrome, and for determining structural aberrations of the $\mathrm{Y}$ chromosome. ${ }^{11}$

Only about 40 to $60 \%$ of Turner's syndrome patients are monosomic for the $\mathrm{X}$ chromosome. ${ }^{12}$ The remaining Turner patients usually have a structurally abnormal X chromosome $(16 \%)$ or a mosaic karyotype $(18 \%)$. The detection of chromosomal mosaicism depends on the number of cells examined, ${ }^{13}$ the type of tissue studied, the sensitivity of the method applied, and whether in vivo or in vitro selection against one of the cell lines occurs. ${ }^{1415}$ In mosaics, a second line of cells may contain structurally normal or abnormal sex chromosomes (X or $\mathrm{Y}$ ), in various numbers of copies per cell. Detection of $Y$ chromosomal DNA content in the second cell line is of crucial diagnostic importance owing to the fact that phenotypic females with a $\mathrm{Y}$ chromosome and gonadal dysgenesis have an approximately $20 \%$ risk of developing gonadoblastoma ${ }^{16}$ which necessitates surgical removal of the gonads.

In other cases of abnormality of sexual differentiation, for example, patients with small, structurally abnormal marker chromosomes which may be derivatives of the $Y$, the identity of such marker chromosomes may be difficult to determine by classical cytogenetic methods. However, the application of molecular techniques combined with cytogenetics may greatly improve the speed and accuracy of such diagnoses and may also be used retrospectively to confirm or negate previously made diagnoses.

The alphoid (alpha) satellites comprise a primate specific family of tandemly repeated sequences present in pericentromeric regions of all human chromosomes. ${ }^{17}$ Despite sequence similarities this is the only repetitive DNA family exhibiting significant chromosomal specificity. This includes the $\mathrm{Y}$ chromosome specific sequences. ${ }^{18}$ In classical cytogenetics chromosome specific alphoid probes have become a tool for the detection of specific chromosome aberrations and for the definition of marker chromosomes. ${ }^{1920}$ Using PCR primers that recognise chromosome specific regions of alphoid monomers, one can easily generate chromosome specific probes for in situ hybridisation, ${ }^{21}$ characterise somatic cell hybrids, ${ }^{22}$ or define structural chromosomal aberrations. ${ }^{23}$

A sex diagnostic procedure using detection of Y chromosomal alphoid DNA by means of blotting/hybridisation has previously been described. ${ }^{5}$ In this paper we present an application of an improved, PCR based method of detection of $\mathrm{Y}$ chromosomal alphoid DNA, developed previously by us $^{78}$ for the rapid, sensitive, and cost effective screening of patients with abnormalities of sexual differentiation for $\mathrm{Y}$ chromosomal DNA content.

\section{Patients, materials, and methods}

All patients were seen at the Department of Medical Genetics, Medical Academy in Poznań, Poland or at the General Hospital of Mexico in Mexico City, Mexico.

Genomic DNA was isolated from peripheral blood by standard methods. ${ }^{24}$ For the polymerase chain reaction (PCR) analysis of alphoid sequences of the $\mathrm{Y}$ and $\mathrm{X}$ chromosomes, two sets of $20 \mathrm{mer}$ primers, Y1,Y2 and $\mathrm{X} 1, \mathrm{X} 2$ respectively, were applied; sequences of these primers have been described previously. ${ }^{78}$ A typical PCR protocol ${ }^{25}$ with some
Correspondence to Dr Witt. Received 13 August 1992 Revised version accepted 26 October 1992 
modifications was used with a cycle of $94^{\circ} \mathrm{C}$ for one minute, $57^{\circ} \mathrm{C}$ for one minute, and $72^{\circ} \mathrm{C}$ for one minute, repeated 30 times. PCR products, $170 \mathrm{bp}$ and $130 \mathrm{bp}$, were detected in $3 \%$ NuSieve/1\% regular agarose. All DNA samples for amplification with $\mathrm{Y} 1, \mathrm{Y} 2$ primers were digested with $E c o$ RI before amplification.

In some cases DNA was extracted from blood spotted onto filter paper which had been autoclaved and short wave length UV irradiated to avoid contamination with foreign DNA. ${ }^{7}$ Spots were air dried, sealed in plastic bags, and mailed overseas to our laboratory by regular mail service.

For SRY amplification, primers XES7 and XES2 were used and a previously described protocol ${ }^{26}$ was followed. The 609 bp PCR product was detected in $2 \%$ agarose.

The polymerase chain reaction was run on a programmable thermal controller (MJ Research Inc). Oligonucleotide primers were synthesised on an Applied Biosystems 391 PCR Mate DNA synthesiser. To minimise false positive results, all reaction mixtures were short wave length UV irradiated for five minutes before PCR, and all molecular procedures were performed by a female technician.

Chromosome preparations from peripheral lymphocytes for karyotype studies were obtained according to Latos-Bielenska and Hameister. ${ }^{27}$ Slides were stained by GTG, $\mathrm{QFQ}, \mathrm{RBG}$, and CBG standard banding techniques.

\section{Results and discussion}

When the previously described method ${ }^{78}$ for detection of $Y$ chromosomal DNA by amplification of alphoid repeats was routinely used for diagnostic purposes, the expected Y specific signal (diagnostic band $170 \mathrm{bp}$ ) was detected only in normal males, but not in normal female controls (figure A, table). The specificity of the diagnostic signal was effectively enhanced by slightly raising the annealing temperature above that originally published (higher stringency), and by digestion of template DNA before amplification with $E c o$ RI, since the $170 \mathrm{bp}$ fragment to be amplified does not contain restriction sites for this enzyme. In all cases control amplification with the $\mathrm{X}$ specific primers resulted in amplification of the $130 \mathrm{bp}$ segment of alphoid repeats of the $\mathrm{X}$ chromosome (control band $130 \mathrm{bp}$ ) (figure A).

To estimate the range of sensitivity of the method, male and female DNA was mixed in varying proportions to mimic certain Turner's syndrome mosaics, reconstitution in some bone marrow recipients, certain amniotic fluid/chorionic villi samples, or male fetal cells in maternal circulation. The $\mathrm{Y}$ specific alphoid PCR product was easily detectable in ethidium bromide stained agarose gel, even when male DNA constituted as little as $0.01 \%$ of the mixture (figure A). This corresponds to a total of at most $100 \mathrm{pg}$ of male genomic DNA on a female background. Similar results were obtained when peripheral blood of males and
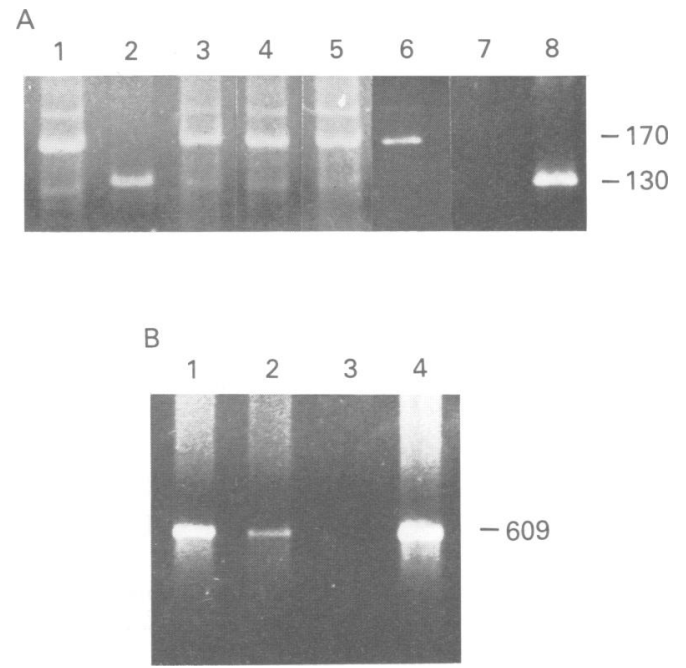

(A) PCR of mixtures of female DNA with decreasing quantities of male DNA in the presence of specific primers for alphoid repeats: lane 1, 100\% male blood, primers $Y 1, Y 2$; lane 2, $100 \%$ male blood, primers $X 1$, $X 2$; lane 3, 10\% male blood, primers $Y 1$, Y2; lane 4, $1 \%$ male blood, primers $Y 1, Y 2$; lane $5,0 \cdot 1 \%$ male blood, primers $Y 1, Y 2$; lane $6,0.01 \%$ male blood, primers $Y 1, Y 2$; lane $7,100 \%$ female blood, primers $Y 1, Y 2$; lane $8,100 \%$ female blood, primers $X 1, X 2$. Positions of $170 \mathrm{bp}$ and $130 \mathrm{bp}$ bands indicated on the right. (B) PCR of human genomic DNA in presence of SRY specific primers: lane $1,45, X / 46, X$,idic ( $Y)$ (q11.23), $52 \% / 48 \%$; lane $2,45, X / 46, X$,idic $(Y)(q 11.23)$, $88 \% / 12 \%$; lane 3, normal female control; lane 4, normal male control. Position of a $609 \mathrm{bp}$ band indicated on the right.

females was mixed and spotted on filter paper, DNA eluted, and used as a template for PCR (data not shown). The major advantage of this diagnostic procedure is that it does not require radioactive isotopes, in contrast to previous methods, ${ }^{159}$ although it still exhibits extreme sensitivity for detection of $\mathrm{Y}$ specific sequences. This makes this method useful for detecting $\mathrm{Y}$ material even in low percentage mosaics. That this is an isotope free method and does not need tedious hybridisation techniques should be especially appreciated in molecular diagnostic laboratories performing this kind of procedure routinely.

Because of the high sensitivity of the method it is necessary to take precautions to avoid even the slightest contamination with foreign DNA and for this reason we isolate DNA with extreme caution, UV irradiate all PCR reaction mixtures (before addition of dNTPs, primers, and DNA), use separate sets of chemicals and equipment, and digest DNA with relevant restriction enzymes. None of the experimental steps is performed by a male.

Results of blind studies of 28 patients with abnormalities of sexual differentiation applying the described method fully confirmed its usefulness for analysis of mosaics in these disorders (table). In none of the cases without a Y chromosome detected cytogenetically was a positive $\mathrm{Y}$ chromosomal alphoid PCR signal obtained (groups 1 and 2). As expected, supernumerary $\mathrm{X}$ chromosomes did not influence the amplification pattern with either $\mathrm{Y}$ or $\mathrm{X}$ specific alphoid primers (group 2). In all cases with the $\mathrm{Y}$ chromosome present, either in all or some cells only, the $\mathrm{Y}$ specific alphoid band was amplified (groups 3 to 6 ). Five mosaic 
Comparison of amplification of alphoid centromeric repeats of the $Y$ and the $X$ chromosomes and of the SRY sequence.

\begin{tabular}{llcccc}
\hline Group & Karyotype (phenotype) & $\begin{array}{c}\text { Alphoid } \\
\text { Y }\end{array}$ & $\begin{array}{c}\text { Alphoid } \\
\text { X }\end{array}$ & SRY & $\begin{array}{c}\text { No of } \\
\text { cases }\end{array}$ \\
\hline 1 & $45, X$ (female) & - & + & - & 15 \\
2 & $45, X / 46, X X / 47, X X X$ (female) & - & + & ND & 3 \\
3 & $46, X Y$ (female) & + & + & + & 1 \\
4 & $45, X / 46, X Y$ (male) & + & + & + & 3 \\
5 & $45, X / 46, X Y$ (female) & + & + & + & 5 \\
6 & $45, X / 46, X+$ marker (female) & + & + & + & 5 \\
7 & $46, X X$ (normal female control) & - & + & + & 5 \\
\hline & $46, X Y$ (normal male control) & + & + & &
\end{tabular}

$\mathrm{ND}=$ not determined. regular mail from a laboratory located abroad. This illustrates in practice the technical ease of application of this method for molecular laboratories collaborating with distant hospitals.

The authors thank Drs Robert P Erickson and Stan $\mathbf{R}$ Blecher for critical reading of this manuscript and Dr Susana Kofman-Alfaro for help in collection of dried blood specimens. This work was supported in part by a grant 4 47349203 from the Committee for Scientific Research to $\mathrm{MW}$.

cases with marker chromosomes of unknown origin (group 6) were found to be positive for presence of the $\mathrm{Y}$ chromosomal alphoid sequences. Consequently all five marker chromosomes were further identified as derivatives of the $\mathrm{Y}$, specifically as isodicentric $\mathrm{Y}$ chromosomes with breakpoints at Y11.22 or Yq11.23. In this study a cytogenetic investigation was used to confirm PCR derived results. Obviously, this method is not applicable to those rare situations in which centromeric sequences are deleted, for example, certain cases of 46,XX males with translocation of part of $\mathrm{Yp}$ to the $\mathrm{X}$ chromosome.

The sensitivity of this method makes it especially useful for detection of mosaicism in peripheral blood cells in which the second cell line may be expressed at a lower percentage than in the embryo or in other tissues owing to in vivo selection. The selective loss of the second line could be caused either by a shortened lifespan of cells containing marker chromosomes or by increased chromosomal instability of marker chromosomes that undergo complex rearrangements. ${ }^{15}$ One can think of clinical cases for which sensitivity of cytogenetic techniques might be not sufficient and this PCR based method would be the only source of reliable diagnostic information.

Amplification of a fragment of the SRY gene $^{26}$ was used for comparison (table, figure B). This locus is considered to be a specifically male sequence that meets many of the criteria expected of the testis determining factor (TDF). The pattern of signal distribution was identical to that of the $\mathrm{Y}$ specific alphoid primers. Although quantification of the $\mathrm{Y}$ specific product has not been performed, we were able to visualise repeatedly a variation in intensity of the specific product band, which might reflect differences in the $\mathrm{Y}$ chromosome template content in mosaics that were studied (figure B). The disadvantage of using SRY for detection of the $\mathrm{Y}$ chromosome may become crucial in very low percentage mosaics since SRY is a single copy gene ${ }^{28}$ and, also, in cases of deletion of $Y p$ or fragments of $Y p$ of various sizes containing SRY. The $Y$ chromosome with deletion of its short arm can still act as a factor predisposing to gonadoblastoma, since the postulated GBY gene (gonadoblastoma locus on $\mathrm{Y}$ chromosome) has been preliminarily mapped to the region including deletion intervals $4 B$ to 7 , that is, it is located near the centromere or on the long arm of the Y.2930

The other diagnostic advantage is the successful use of dried blood spots as an efficient source of DNA. All spots were sent to us by
1 Lau YF, Dozy AM, Huang JC, Kan YW. A rapid screening test for antenatal sex determination. Lancet 1984;i:14-16. test for antenatal sex determination. Lancet $1984 ; \mathbf{i}: 14-16$.
Lau YF, Schonberg A. A male-specific DNA probe detects heterochromatin sequences in a familial Yq-chromosome. Am $\mathcal{F}$ Hum Genet 1984;36:1394-6.

3 Lau YF. Detection of Y-specific repeat sequences in normal and variant human chromosomes using in situ hybridization with biotinylated probes. Cytogenet Cell Genet 1985;39:184-7.

4 Disteche C, Luthy I, Haslan DB, Haar D. Prenatal identifi$\mathrm{Y}$-specific repetitive DNA probe. Hum Genet 1984;67:222-4.

5 Stalvey JRD, Erickson RP. An improved method for detecting $Y$ chromosomal DNA. Hum Genet 1987;76:240-3.

6 Kogan SC, Doherty M, Gitschier J. An improved method for prenatal diagnosis of genetic diseases by analysis of for prenatal diagnosis of genetic diseases by analysis of 90 .

7 Witt M, Erickson RP. A rapid method for detection of Ychromosomal DNA from dried blood specimens by the polymerase chain reaction. Hum Genet 1989;82:271-4.

8 Witt M, Erickson RP. A rapid method for detection of $Y$ chromosomal DNA from dried blood specimens by the polymerase chain reaction (erratum). Hum Genet 1991;86:540.

9 Ebensperger C, Studer R, Epplen JT. Specific amplification of the ZFY gene to screen sex in man. Hum Genet 1989;82:289-90.

10 Lawler M, McCann SR, Conneally E, Humphries P. Chimerism following allogeneic bone marrow transplantachain reaction. Br $\mathcal{f}$ Haematol 1989;73:205-10.

11 Stalvey JR, Erickson RP, Dasouki M, Glover T, Shokir M. Clarification of chromosomal abnormalities with sexual Clarification of chromosomal abnormalities with sexual quences. Cytogenet Cell Genet 1988;47:140-3.

12 Fryns JP, Kleczkowska A, van den Berghe $H$. The $\mathrm{X}$ chromosome and sexual development: clinical aspects. In: Sandberg AA, ed. Cytogenetics of the mammalian $X$ chromosome. Part B. X chromosome anomalies and their clinical manifestations. New York: Alan R Liss, 1983:115-26.

13 Hook EB. Exclusion of chromosomal mosaicism: tables of use. Am F Hum Genet 1977;29:94-7.

14 Procter SE, Watt JL, Lloyd DJ, Duffty P. Problems of detecting mosaicism in skin. A case of trisomy 8 mosaicism illustrating the advantages of in situ tissue culture. Clin Genet 1984;25:273-7.

15 Held KR, Kerber S, Kaminsky E, et al. Mosaicism in 45, X Turner syndrome: does survival in early pregnancy Turner syndrome: does survival in early pregnancy
depend on the presence of two sex chromosomes. Hum depend on the presence
Genet 1992;88:288-94.

16 Verp MS, Simpson JL. Abnormal sexual differentiation and neoplasia. Cancer Genet Cytogenet 1987;25:191-218.

17 Willard HF, Waye JS. Hierarchical order in chromosomespecific human alpha satellite DNA. Trends Genet 1987;3:192-8.

18 Wolfe J, Darling SM, Erickson RP, et al. Isolation and characterization of an alphoid centromeric repeat family from the human $\mathrm{Y}$ chromosome. $f \mathrm{Mol} B$ Biol interphase and metaphase assessment of specific chromosomal changes in neuroectodermal tumor cells by in situ hybridization with chemically modified DNA probes. Exp hell Res 1988;176:199-220.

20 Poddighe PJ, Moesker O, Smeets D, Awwad BH, Ramaekers CS, Hopman AHN. Interphase cytogenetics Ramaekers CS, Hopman AHN. Interphase cytogenetics of hematological cancer: comparison of classical karyotyping and in situ hybridization using a panel of eleven chromosome speci

21 Dunham I, Lengauer C, Cremer T, Featherstone T. Rapid generation of chromosome-specific alphoid DNA probes using the polym

22 Erickson RP, Glover T, Hall BK, Witt M. Polymerase chain reactions with alphoid-repeat primers in com1991;55:199-211. tion mapping of interval 6 of the human $\mathrm{Y}$ chromosome. Hum Genet 1991;87:234-6.

24 Kunkel LM, Smith KD, Boyer SH, et al. Analysis of cation of a deleted $\mathrm{Y}$ chromosome by cytogenetics and a tion: detection of residual host cells using the polymerase $90 \%, 95 \%$, and $99 \%$ confidence limits and comments on 1985;182:477-85.

19 Cremer T, Tesin D, Hopman AH, Manuelidis L. Rapid bination with Alu or LINEs primers, generate chromosome-specific DNA fragments. Ann Hum Genet

23 Kotecki M, Jaruzelska J, Skowronska M, Fichna P. Dele- 
human Y chromosome-specific reiterated DNA in chromosome variants. Proc Natl Acad Sci USA 1977;74:1245-9.

25 Saiki RK, Gelfand DH, Stoffel S, et al. Primer-directed enzymatic amplification of DNA with thermostable DNA polymerase. Science $1988 ; 239: 487-91$.

26 Berta P, Hawkins JR, Sinclair AH, et al. Genetic evidence equating SRY and the testis determining factor. Nature 1990;348:448-50.

27 Latos-Bielenska A, Hameister $\mathrm{H}$. Higher resolution banding technique in the clinical routine. Clin Genet 1988;33:325-30
28 Sinclair AH, Berta P, Palmer MS, et al. A gene from the human sex-determining region encodes a protein with homology to a conserved DNA-binding motif. Nature homology to a

29 Page DC. Hypothesis: a Y-chromosomal gene causes gonadoblastoma in dysgenetic gonads. Development (Suppl) 987;101:151-5

30 DeArce MA, Costigan C, Gosden JR, Lawler M, Humphries $\mathrm{P}$. Further evidence consistent with $\mathrm{Yqh}$ as an indicator of risk of gonadal blastoma in Y-bearing mosaic Turner syndrome. Clin Genet 1992;41:28-32. 